\title{
BRAGANTIA
}

Revista Científica do Instituto Agronômico, Campinas

Vol. 40

Campinas, junho de 1981

Artigo n. ${ }^{\circ} 10$

\section{PICADAS DE ALIMENTAÇÃO DE NEZARA VIRIDULA EM CULTIVARES E LINHAGENS DE SOJA DE DIFERENTES GRAUS DE SUSCETIBILIDADE ( $\left.{ }^{(}\right)$}

C. J. Rossetto, A. L. Lourenção $\left(^{2}\right)$, Seção de Entomologia Fitotécnica, T. Igue, Seção de Técnica Experimental e Cálculo, e M. A. C. DE Miranda ${ }^{(2)}$, Seção de Leguminosas, Instituto Agronomico

\section{RESUMO}

O número de vezes que o percevejo-verde Nezara viridula (L., 1758) (Hemiptera: Pentatomidae) se alimentou em cinco diferentes genótipos de soja foi estimado através das bainhas do estilete que permaneceram no local onde ele se alimentou. Foram feitas estimativas a olho nu, através de lupa sem corante e através de lupa após tratamento das vagens com corante de fucsina ácida, como foi proposto por BOWLING. A olho nu, notaram-se distintamente os locais das picadas nos cultivares Paraná e Hill e muito poucas picadas nas linhagens IAC 73/228 e IAC 77/656. A primeira geração do cruzamento entre 'Paraná' e IAC 73/228 apresentou comportamento intermediário, quando observada sem corante. Após tratarem-se as vagens com corante, ficou reduzida a diferenciação entre as linhagens IAO e os cultivares Hill e Paraná, enguanto a geração $F_{1}$ deixou de ser intermediária e igualou-se aos cultivares suscetiveis. Os resultados sugerem a presença de um grau alto de tolerância à alimentaçăo de percevejo nas linhagens IAC $73 / 228$ e IAC $77 / 656$.

\section{INTRODUÇÃO}

N. viridula é um percevejo praga importante para a cultura da soja em quase todo o mundo, ocorrendo na Austrália, Ásia, Äfrica, América do Norte e América do Sul (5). MIRAN$\mathrm{DA}$ et alii (4) relataran que, em Campinas (SP), a linhagem de soja IAC $73 / 228$ é menos danificada pelo ata- que de percevejos em condições de campo. Até essa observação não havia à disposição dos melhoristas de soja do mundo nenhuma fonte de resistência alta a percevejos conhecida para a cultura da soja. A resistência da linhagem IAC $73 / 228$ oferece, portanto, aos entomologistas e me-

(1) Recebido para publicação a 17 de setembro de 1980. Patrocinado pelo acordo IAC-FINEF Contrato 400/CrT e pelo Plano Integrado de Parasitologia Agrícola do CNPa. Agradecimentos săo devidos ao estagiário ARIL70 FORTE e aos senhores AIDO FERNANDFS. ARCHANGELO MARION, OSVALDO FEDERICCI e MARIA INES FONSECA JORGE, da Seçâo de Entomologia Fitotécnica, pela ajuda na execuçào do trabalho.

(2) Com bolsa de suplerientação do CNPq. 
lhoristas de soja uma perspectiva nova para reduzir biologicamente, sem prejuízos ecológicos e sem exigir gastos dos agricultores, parte significativa dos danos causados por espécies de percevejos pentatomídeos à soja. Torna-se necessário esclarecer o tipo ou os tipos de resistência envolvidos na linhagem IAC 73/228: um que poderia estar envolvido é o de não preferência para alimentação nas vagens da linhagem IAC 73/228.

BOWLING $(\mathbf{1}, 2)$ descreveu uma técnica para contar picadas de alimentação do percevejo Oebalus pugnax em grãos de arroz e do percevejo N. viridula em vagens de soja.

No presente trabalho, utilizou-se essa técnica para estimar o número de vezes que os percevejos da espécie N. viridula se alimentaram das vagens da linhagem resistente IAC $73 / 228$ e de cultivares suscetíveis.

\section{MATERIAL E METODOS}

Utilizaram-se cinco diferentes genótipos de soja (quadro 1), sendo um referido por MIRANDA et alii (4) como muito danificado por percevejos, o cultivar Paraná, e outro como pouco danificado, a linhagem IAC $73 / 228$, além da geração $F_{1}$ do cru- zamento 'Paraná' x IAC 73/228. Outro cultivar testado foi o Hill, que, curiosamente, é ancestral tanto do cultivar suscetível Paraná como da linhagem resistente IAC 73/228. Foi utilizada ainda a linhagem IAC $77 / 656$, que se tem destacado pela alta produtividade e que foi obtida do cruzamento de uma linhagem irmã da IAC $73 / 228$ - a IAC 73/231 com o cultivar Paraná.

As sementes foram tratadas com inoculante $\left({ }^{3}\right)$. Os genótipos, dis'ribuídos em blocos ao acaso com dez repetições, foram semeados a 12-05-80, usando-se três sementes por vaso de alumínio com capacidade para 16 litros de terra. Os vasos foram colocados em casa de vegetação da Seção de Entomologia Fitotécnica, no Centro Experimental de Campinas. Com $15 \mathrm{~cm}$ de altura, as plantas foram desbastadas, deixando-se uma por vaso. Por ocasião do florescimento, cerca de 500 adultos de $\mathbf{N}$. viridula criados em soja foram colocados diretamente sobre as plantas, com liberdade para escolha entre os genótipos.

A 16-07-80, quando as plantas atingiram o estádio R5, estádio de vagens verdes com grãos em desenvolvimento, segundo a classificação de FEHR et alii (3), efetuaram-se as ava-

QUADRO 1 - Genótipos de soja estudados e suas origens

\begin{tabular}{|c|c|}
\hline Genótipos & Origem \\
\hline 'Paraná' & 'Hill' x D 52/810 \\
\hline $\mathbf{F}_{1}$ & 'Paraná' x IAC $73 / 228$ \\
\hline IAC $73 / 228$ & 'Hill' x PI 274454 \\
\hline 'Mill' & \\
\hline IAC $77: 656$ & 'Paraná' x IAC $73 / 231$ \\
\hline
\end{tabular}


liações do número de picadas de alimentação dos percevejos nas vagens.

Para avaliação das picadas, utilizaram-se três métodos diferentes. Contaram-se, a olho nu, as marcas escuras deixadas pelas picadas do percevejo em cinco vagens de cada uma das plantas. Guardaram-se essas vagens em geladeira e, pouco a pouco, colocaram-nas através de lupa, no laboratório, contando-se as marcas deixadas pela picada. Depois, essas cinco vagens de cada planta foram envolvidas em atadura de pano $e$ imersas no corante vermelho recomendado por BOWLING (2) para contagem das picadas de alimentação de N. viridula em soja. guinte:

A fórmula do corante é a se-

Fenol - uma parte

Ácido lático - uma parte

Água destilada - uma parte

Glicerina - duas partes

Fucsina ácida - quantidade suficiente para ficar bem vermelho.

As vagens, após permanecerem no corante por 20 horas (recomenda-se o mínimo de quatro horas (2), foram retiradas e lavadas em água corrente. Ainda envolvidas na atadura, foram colocadas na geladeira e retiradas pouco a pouco, para contagem das picadas de alimentação através de lupa. As picadas ficam coloridas de vermelho-escuro no fundo verde da vagem.

A área de cada vagem foi estimada, utilizando-se papel manilha, onde se desenharam as vagens, recortando-se e pesando-se os desenhos do papel. Comparando-se com o peso obtido de $100 \mathrm{~cm}^{2}$ do pupel, estimou- -se a superfícic externa total das duas faces da vagem.

\section{RESULTADOS E DISCUSSÃO}

Pelos resultados obtidos, sumariados no quadro 2 , verifica-se que as contagens feitas a olho nu e através de lupa sem corante são semelhantes. A utilização do corante tornou mais visível o número de picadas observadas em todos os tratamentos, especialmente nas linhagens que apresentavam poucas picadas visíveis a olho nu, IAC 73/228 e IAC $77 / 656$.

Observadas a olho nu, as linhagens IAC $73 / 228$ e IAC $77 / 656$ apresentaram número pequeno de picadas visíveis. A linhagem IAC 73/ 228, já referida como pouco danificada por percevejos em condições de campo (4), confirma esse comportamento em estufa.

A linhagem IAC 77/656 apresentou comportamento semelhante à IAC $73 / 228$, o que sugere que será pouco danificada por percevejos em condições de campo. Essa linhagem é de boa produtividade, além de ter outras características agronômicas desejáveis, oferecendo a possibilidade de ser liberada para cultivo no Estado de São Paulo.

O cultivar Hill apresentou comportamento semelhante ao 'Paraná', sugerindo ser muito suscetível a percevejos.

O fato de o 'Hill' ser a origem do 'Paraná' (quadro 1), explica a alta suscetibilidade do último observada por MIRANDA et alii (4) em condições de campo. O 'Hill' também deu origem à linhagem resistente IAC $73 / 228$, deduzindo-se, portanto, que a resistência da linhagem IAC 73/228 a percevejos é proveniente da Pl 


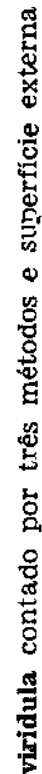

乙

용

氶

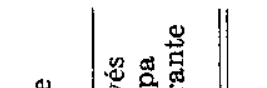

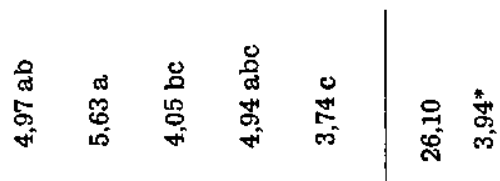

总

蔃

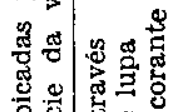

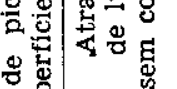

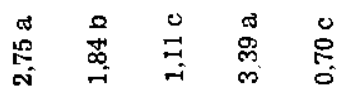

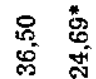

造

芴

g

$\vec{a}$
䙲
4

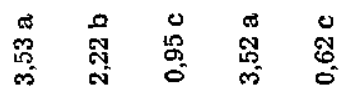

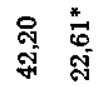

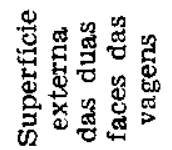

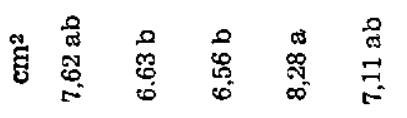

है

5

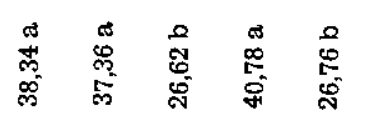

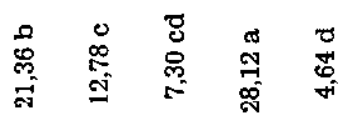

व्ठ

$\$$

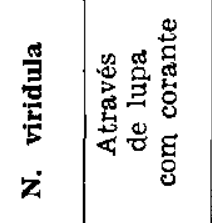

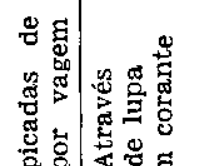

象

๑.

造

边

के

व

\&

.

융

옹

类

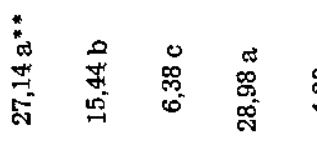

요

(1)

藏

芯

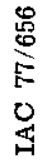

\& $\stackrel{*}{\circ}$ 용

命 थ

总

운

要

$1 \%$

$\infty$

突

?

总

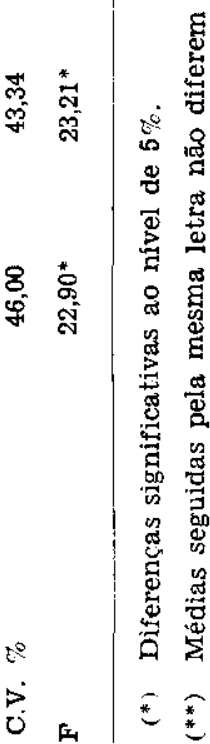


274454. Esse é um material introduzido de hábito de crescimento procumbente, vigoroso, muito tardio, originário da ilha japonesa de Okinawa.

A linhagem IAC 77/656 é descendente de um cruzamento do cultivar Paraná com IAC $73 / 231$, linhagem irmã da IAC $73 / 228$, pois ambas derivaram do mesmo cruzamento, 'Hill' x PI 274454 (quadro 1). A provável resistência a percevejos da IAC $77 / 656$, portanto, também é derivada da PI 274454.

O fato de o 'Hill' dar origem a um cultivar tão suscetível quanto ele mesmo, que é o Paraná, e de uma linhagem resistente a percevejo, como a IAC $73 / 228$, demonstra que a resistência ou suscetibilidade a percevejos provavelmente seja uma característica de herança simples, governada por poucos genes, que pode ser facilmente transferida para plantas descendentes e que não está ligada a outras características agronômicas indesejáveis, podendo ser utilizada no melhoramento da soja.

Pelo quadro 2 , về-se que a geração $F_{1}$ do cruzamento 'Paraná' $x$ IAC $73 / 228$, na contagem feita a olho nu, ficou numa posição intermediária entre os dois pais, enquanto na contagem feita com corante apresentou comportamento igual ao da mãe suscetível. A interpretação desse resultado não pode ser feita com segurança apenas com as informações disponíveis até o momento.

Quando a contagem de picadas foi feita com corante, ficou reduzida a diferença entre as linhagens pouco picadas IAC $73 / 228$ e IAC $77 / 656$ e os cultivares muito picados Hill e
Paraná, mas ainda assim a diferença foi significativa. Isso sugere a existência de um grau moderado de não preferência para alimentação nas linhagens IAC $73 / 228$ e IAC $77 / 656$. Quando a contagem foi feita a olho nu, essa diferença ficou ampliada (quadro 2), sugerindo a existência de um alto grau de tolerância às picadas nas linhagens IAC $73 / 228$ e IAC 77/656. Estas, além de terem sido menos picadas, mostraram uma pequena reação da planta no local da picada, pouco visível a olho nu. Observações sobre o comportamento de alimentação do inseto nesses genótipos resistentes e suscetíveis são necessárias para confirmar ou não a existência de um baixo grau de não preferência para alimentação nas referidas linhagens.

A transformação dos resultados do número de picadas por unidade de área (quadro 2) praticamente não alterou os resultados.

\section{CONCLUSŌES}

a) Os métodos de contagens de picadas de percevejos sem corante e com corante são úteis para o estudo dos tipos de resistência de soja a percevejos.

b) A resistência a percevejos, observada nas linhagens IAC $73 / 228$ e IAC $77 / 656$, é, em grande parte, devida à tolerância à picada do percevejo.

c) A linhagem IAC 77/656, que tem apresentado bom comportamento agronômico em testes de produtividade, comportou-se como resistente em relação ao percevejo $\mathbf{N}$. viridula. 


\section{STYLET SHEATH OF NEZARA VIRIDULA IN RESISTANT AND SUSCEPTIBLE SOYBEAN VARIETIES}

\section{SUMMARY}

The number of stylet, sheaths of Nezara viridula ( $L$, 1758) (Hemiptera: Pentatomidae) in 5 soybean (Glycine $\max$ (L.) Merrill) varieties was estimated under greenhouse conditions, at Campinas, State of Sāo Paulo, Brazil.

When estimated with naked eyes, the number of stylet sheaths was low in the varieties IAC $73 / 228$ and IAC $77 / 656$, high in the commercial varieties 'Hill' and 'Parana' and intermediate in the $F_{1}$ generation between Paraná and IAC 73/228. When estimated under the stereo microscope after staining the pods with acid fucsin, the number of stylet sheaths was high in the commercial varieties 'Hill', 'Paraná' and the $F_{1}$. It was intermediate in IAC $73 / 228$ and IAC $77 / 656$. It seems from these results that a moderate degree of non preference for feeding might be present in the varieties IAC $73 / 228$ and IAC 77/656, but further research is needed to support or to reject the existence of this moderate degree of non preference.

The varieties IAC $73 / 228$ and IAC $77 / 656$ showed low stylet sheath counts when the pods were not stained and higher counts after staining. This suggests that they have high tolerance to the feeding activity of the green stink bug, not showing much reaction to its feeding activity. It is easier to notice the feeding punctures of the green stink bug on the pods of susceptible varieties than on resistant varieties.

The variety IAC $73 / 228$ has been previously shown to suffer low damage caused by green stink bug under field conditions. Both IAC $73 / 228$ and IAC $77 / 656$ are descendents of crosses involving the PI 274454 with the susceptible commercial variety 'Hill'. The PI 274454 is probably a good source of resistance to the green stink bug. It is a vigorous, procumbent, late maturing variety from the Japanese island of Okinawa.

\section{REFERENCIAS BIBLIOGRAFICAS}

1. BOWLING, C.C. The stylet sheath as an indicator of feeding activity of the rice stink bug. Journal Economic Entomology, 72(2):259-260, 1979.

2. - The stylet sheath as an indicator of feeding activity by the Southern green stink bug on soybeans. Journal Economic Entomology, 73(1):1-3, 1989.

3. FEHR, W. R.; CAVINESS, C. E.; BURMOOD, D. T.; PENNINGTON, J. $\mathbf{S}$. Stage of development descriptions for sơybeans, Glycine $\max$ (L.) Merrill. Crop Sciency, 11:929-931, 1971.

4. MIRANDA, M. A. C.; ROSSETTO, C. J.; ROSSETTO, D.; BRAGA, N. R.; MASCARENHAS, H. A. A.; MASSARIOL, A. Resistência de soja a Nezara viridula (L.) e Piezodorus guildinii (Westw.) em condiçōes de campo. Bragantia, Campinas, 38:181-189, 1979.

5. SINGH, S. R. \& EMDEN, H. F. van. Insect pests of grain legumes. Annual Review of Entomology, 24:255-278, 1979. 